\title{
Comunicação
}

[Communication $]$

\section{Transposição e anastomose uretral pré-púbica em um cão macho com estenose extensa da uretra intrapélvica}

\author{
[Prepubic urethral transposition in a male dog with extensive stenosis \\ of the pelvic urethra] \\ P. Vives ${ }^{1}$, F.A. Braga ${ }^{2}$, J. Rappeti ${ }^{2}$, V. Milech ${ }^{3}$, B. Maroneze ${ }^{3}$, G. Möller ${ }^{3}$, \\ S. Rausch ${ }^{2}$, E.S. Moraes ${ }^{2}$, A. Mazzanti ${ }^{4}$ \\ ${ }^{1}$ Aluno de Pós-graduação - Universidade Federal de Santa Maria - UFSM - Santa Maria, RS \\ ${ }^{2}$ Universidade Federal de Pelotas - UFPel - Pelotas, RS \\ ${ }^{3}$ Residência em Cirurgia Veterinária - UFPel - Pelotas, RS \\ ${ }^{4}$ Universidade Federal de Santa Maria - Santa Maria, RS
}

As lesões da uretra intrapélvica (membranosa) são consideradas de baixa ocorrência devido à conformação anatômica protegida; mesmo assim, o reparo é considerado desafiante para os cirurgiões urologistas em decorrência das complicações observadas como estenose (Ximenes e Souza Neto et al., 2010; Kemper et al., 2011). A estenose uretral é uma das principais causas das disfunções miccionais (Ghozzi et al., 2010) em cães e frequentemente está relacionada a traumas no trato urinário associados às fraturas pélvicas (Kemper et al., 2011).

Os sinais de estenose uretral incluem hematúria, oligúria ou anúria, com excessiva dilatação do trato urinário, que se inicia pela distensão vesical e causa hidroureter e hidronefrose (Bjorling, 2003). O diagnóstico deve ser realizado por meio de uretrocistografia retrógrada com contraste positivo (URCP) (Raney et al., 1977).

$\mathrm{Na}$ falha do tratamento conservador, recomendase a ressecção da uretra estenosada e anastomose término-terminal com resultados satisfatórios, desde que o comprimento da constrição não ultrapasse um centímetro (Bjorling, 2003). Porém, o reparo de estreitamentos uretrais intrapélvicos extensos torna-se bastante prejudicado devido à dificuldade em minimizar a tensão na anastomose (Raney et al., 1977), além de seguidamente requerer a osteotomia do púbis (Katayama et al., 2012). Na impossibilidade da anastomose, preconiza-se a uretrostomia prépúbica, com ablação da genitália externa (Smeak, 2000).

Na literatura consultada, há raros relatos clínicos de reparo uretral (Regueiro et al., 2012), e diversos experimentos foram realizados utilizando-se mucosa oral, aorta acelular e biomateriais na busca de substitutos de segmentos uretrais, entretanto esses apresentam complicações e requerem mais estudos sobre seu uso (Paulo et al., 2004; Murador, 2013).

O presente trabalho objetiva descrever o tratamento cirúrgico de um cão acometido por estenose extensa da uretra membranosa, por meio de uma nova técnica cirúrgica.

Foi atendido, no Hospital de Clínicas Veterinárias de uma instituição de ensino, um cão macho, adulto, sem raça definida, massa corpórea de $5 \mathrm{~kg}$ e com histórico de trauma por acidente automobilístico, que ocasionou fratura de pelve havia 20 dias. $\mathrm{O}$ paciente apresentava abdome distendido, sensibilidade à palpação e incontinência urinária havia sete dias.

Após avaliação clínica, o cão foi encaminhado ao setor de imagens. A ecografia revelou distensão vesical acentuada com dilatação de ureteres e hidronefrose bilateral (Fig. 1A) e a URCP demonstrou estase do contraste no terço final da uretra membranosa (Fig. 1B).

Recebido em 27 de setembro de 2016

Aceito em 11 de outubro de 2016

* Autor para correspondência (corresponding author)

E-mail: alexamazza@yahoo.com.br 

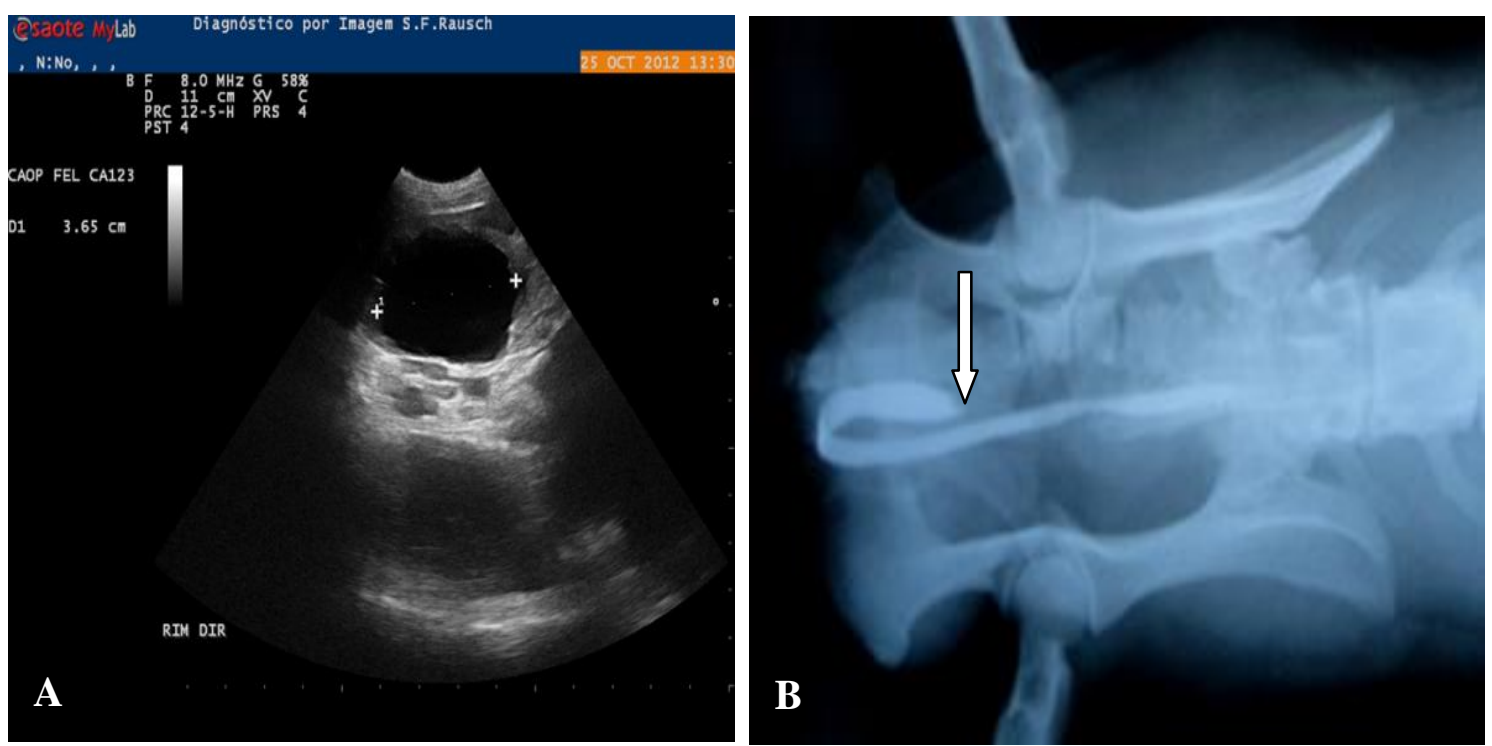

Figura 1. Transposição e anastomose uretral pré-púbica em cão. Em A, verifica-se na ecografia hidronefrose do rim direito (*) em decorrência da estenose da uretra membranosa. Em B, observa-se interrupção do contraste no terço final da uretra membranosa (seta).

Depois de estabilizado e em plano anestésicocirúrgico, o cão foi posicionando em decúbito dorsal, e a uretra peniana sondada até o ponto da estenose. O procedimento consistiu inicialmente de orquiectomia pré-escrotal, seguido de uma incisão longitudinal para mediana retroumbilical (paraprepucial) até o púbis, para acesso à cavidade abdominal. A seguir, fez-se cistocentese e cistotomia na face ventral, objetivando a sondagem da porção uretral proximal para identificar o ponto inicial da estenose; esta progrediu apenas $0,8 \mathrm{~cm}$ caudal à próstata.

Como a lesão uretral no cão deste relato era superior a $2 \mathrm{~cm}$, o que impossibilitava a realização da anastomose término-terminal, optou-se pela transposição uretral pré-púbica. Para isso, realizou-se a secção transversa da uretra a $0,5 \mathrm{~cm}$ caudal à próstata para a ressecção da porção estenosada, e também a secção transversa do pênis a $0,5 \mathrm{~cm}$ caudal ao osso peniano. A uretra, em ambas as extremidades, foi espatulada na sua face ventral (Fig. 2A). Em seguida, a porção peniana foi transposta cranialmente ao púbis, promovendo-se deslocamento moderado para alcançar a uretra prostática.
A sonda, previamente posicionada na uretra peniana, foi introduzida na prostática até alcançar a bexiga, e a anastomose uretral foi realizada por meio de pontos isolados simples, com fio de náilon monofilamentar 4-0, sem que a sutura atingisse a luz do órgão, até completa aposição das bordas (Fig. 2B). A celiorrafia ocorreu de forma rotineira.

Foram prescritos analgesia, antibiótico e manutenção da sonda por sete dias. Exames de URCP foram realizados após a remoção da sonda (Fig. 3A), aos dois meses e quatro anos após a transposição uretral (Fig. 3B), o que evidenciou ausência de constrição uretral.

As lesões da uretra intrapélvica ou membranosa nos cães são pouco comuns e, quando ocorrem, estão frequentemente relacionadas a traumas pélvicos (Boothe, 2000; Kemper et al., 2011) e desencadeiam alterações urinárias, fato observado neste caso. Conforme descrito por Ghozzi et al. (2010), uma das principais causas de disfunção na micção é a estenose uretral, a qual dificulta o esvaziamento vesical, o que contribui para retenção urinária e pode evoluir para hidronefrose nas contrições severas. 


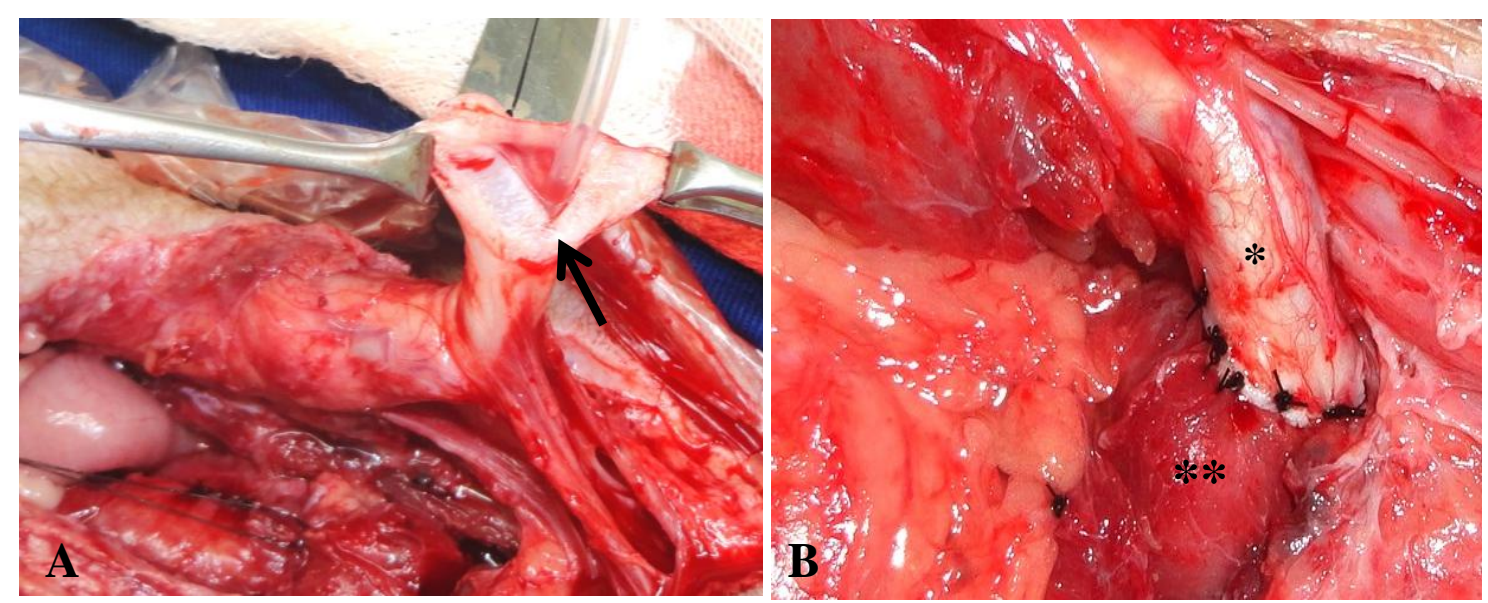

Figura 2. Transposição e anastomose uretral pré-púbica em cão. Em A, nota-se a secção transversal do pênis a $0,5 \mathrm{~cm}$ caudal ao osso peniano e espatulação da face ventral da uretra peniana (seta). Em B, observa-se a completa anastomose entre a uretra peniana $(*)$ e a prostática $(* *)$.
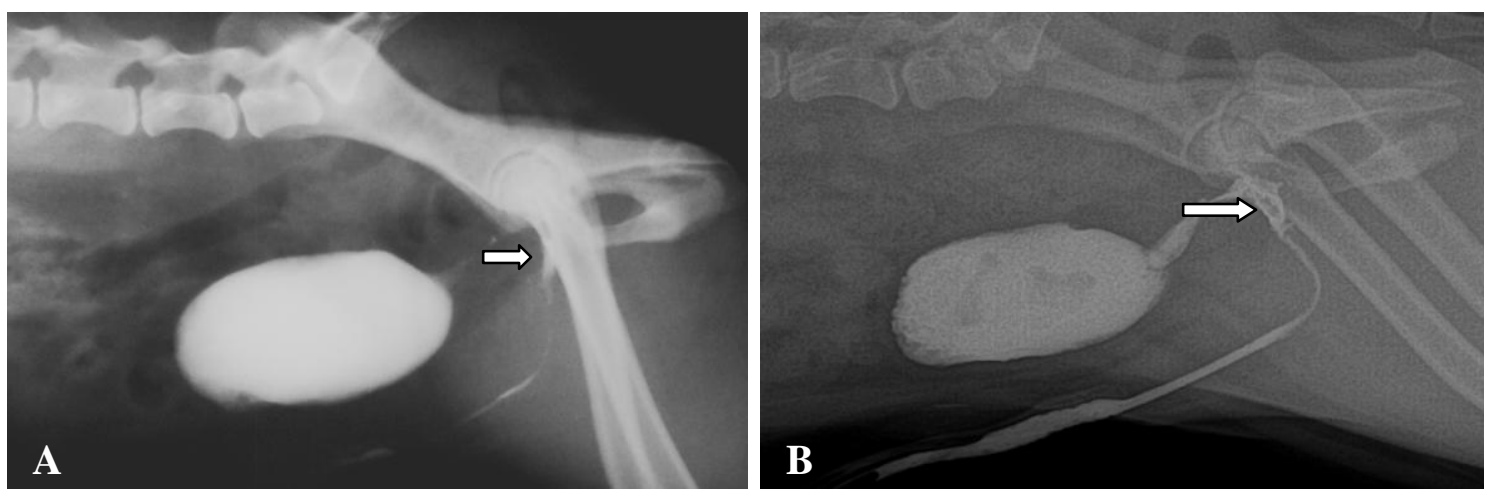

Figura 3. Transposição e anastomose uretral pré-púbica em cão. Nota-se ausência de estenose uretral na anastomose, o que evidencia fluxo do contraste na anastomose (setas), decorridos sete dias (A) e quatro anos de pós-operatório (B), retrospectivamente

A abordagem da uretra membranosa muitas vezes requer osteotomia do púbis (Katayama et al., 2012), o que aumenta a morbidade do procedimento e a dor pós-operatória. A técnica de transposição uretral aqui proposta exclui a osteotomia, uma vez que é executada cranialmente ao púbis e, assim, permite visibilização ampla do campo cirúrgico.

O reparo de estreitamentos uretrais intrapélvicos maiores que um centímetro torna-se bastante limitado devido à dificuldade em minimizar a tensão na anastomose e à rara disponibilidade de opções de substitutos uretrais com baixo custo (Regueiro et al., 2012; Murador, 2013), o que frequentemente leva os cirurgiões veterinários a optarem pela uretrostomia pré-púbica (Katayama, 2012). Entretanto, essa técnica mutilante só é realizada em humanos em casos extremos (Ximenes e Souza Neto et al., 2010), sendo que a transposição não requer implantes, é realizada em apenas um tempo cirúrgico e sem tensão na anastomose.

Defeitos adquiridos, como nas uretrostomias, representam importante etiologia nas infecções complicadas do trato urinário de cães e contribuem para o desenvolvimento de dermatite na junção mucocutânea, o que compromete a qualidade de vida dos pacientes (Bjorling, 2003). Na técnica descrita no presente relato, a genitália externa é mantida, o que, além de eximir a dermatite amoniacal, previne a ocorrência de contaminação vesical.

Embora a principal complicação nas anastomoses uretrais seja a estenose (Regueiro $e t$ al., 2012), o paciente não apresentou constrição 
clínica nem nas URCP subsequentes avaliadas em sete dias, em dois meses e em quatro anos após a intervenção, fato provavelmente relacionado à ausência de tensão na sutura e à espatulação de ambas as bordas da uretra, o que, assim, confere maior diâmetro na anastomose.

Nesse sentido, observa-se a necessidade de maiores estudos em cães com relação a essa técnica, uma vez que não foi encontrada descrição semelhante na espécie canina, apenas em humanos (Ximenes e Souza Neto et al., 2010), entretanto sem transposição pré-púbica.
Conclui-se que a técnica de transposição uretral pré-púbica, embora inovadora, foi uma alternativa viável como tratamento da estenose uretral extensa da uretra membranosa do cão macho do presente estudo, pois restituiu o fluxo urinário, sem evidência de estenose na região de anastomose.

Palavras-chave: cão, obstrução uretral, anastomose, desvio uretral, uretrografia.

\begin{abstract}
We report the use of a new surgical technique in a male dog affected by extensive stenosis of intrapelvic urethra through a antepubic urethral deviation, as an alternative to prepubic urethrostomy and ablation of the external genitalia. The technique consisted initially of orchiectomy, followed by retroumbilical celiotomy, transverse section of the penis in the pre-scrotal region and transposition of this towards the abdominal cavity by making anastomosis to the prostatic urethra. The dog was evaluated clinically and by urethrography retrograde positive contrast for up to four years after the procedure without any clinical signs, changes in urine stream or stenosis image. It is concluded that the pre-pubic urethral transposition is a viable alternative treatment for this dog affected by extensive stenosis of the membranous urethra.
\end{abstract}

Keywords: dog, urethral obstruction, anastomosis, urethral deviation, urethrography

\section{REFERÊNCIAS}

BJORLING, D.E. The urethra. In: SLATTER, D. Textbook of small animal surgery, 3.ed. Philadelphia: Saunders, 2003. v.2, p.1638-1649.

BOOTHE, H.W. Managing traumatic urethral injuries. Clin. Tech. Small Anim. Pract., v.15, p.35-39, 2000.

GHOZZI, S.; GHORBEL, J.; DRIDI, M. et al. Stenose de l'anastomose vesico-urethrale apress prostatectomie radicale (a propos de 7 cas) Service d'Urologie, Hôpital Militaire Principal d'Instructions de Tunis, Tunisie. J. Maroccain D'Urol. v.1, p,23-29, 2010.

KATAYAMA, M.; OKAMURA, Y.; KAMISHINA, H. et al. Urinary diversion via preputial urethrostomy with bilateral pubic-ischial osteotomy in a dog. Turk. J. Vet. Anim. Sci. v.36, p.730-733, 2012.

KEMPER, B.; GONÇALVES, L.P.; VIEIRA, M.O. et al. Consequências do trauma pélvico em cães. Ciênc. Anim. Bras., v.12, p.311-321, 2011.
MURADOR, P. Avaliação histofuncional de matriz heteróloga acelular como scaffold para células de músculo liso para implante em uretra de coelhos. 2013.105f. Tese (Doutorado em Medicina) Faculdade de Medicina de Botucatu, Universidade Estadual Paulista, São Paulo, SP.

PAULO, N.M.; SILVA, F.F.; BRITO, G.A. et al. Reconstrução uretral com retalho autógeno de mucosa bucal após uretrostomia em cães. Acta Cir. Bras., v.19, p.110-114, 2004.

RANEY, A.M.; SCOTT, M.P.; BROWNSTEIN, P.K. et al. Urethral injury - experimental study. Urology, v.9, p.281-283, 1977.

REGUEIRO J.C.; CARRASCO, J.C. et al. Opciones de tratamiento quirúrgico en la estenosis de uretra bulbar. Actas Urol., v.37, p.167-173, 2012.

SMEAK, D.D. Urethrotomy and urethrostomy in the dog. Clin. Tech. Small Anim. Pract., v.15, p.25-34, 2000.

XIMENES, S.F; SOUZA NETO, J.L. Reconstrução uretral. In: NARDOZZA JÚNIOR, A.; ZERATI FILHO, M.; REIS, R.B. Urologia fundamental. São Paulo: Planmark, 2010. cap.36, p.320-326. 